\title{
Multiplicidade de vínculos parentais: Uma análise a partir do princípio do melhor
} interesse

\author{
Multiplicity of parental bonds: A partial analysis of the better interest principle \\ Multiplicidad de lazos parentales: Un análisis basado en el principio del mejor interés
}

Recebido: 04/05/2021 | Revisado: 11/05/2021 | Aceito: 07/07/2021 | Publicado: 17/07/2021

\author{
Tamires Cezimbra Medina \\ ORCID: https://orcid.org/0000-0003-3720-3824 \\ Universidade de Cruz Alta, Brasil \\ E-mail: tamirescezimbramedina@gmail.com \\ Angela Simone Pires Keitel \\ ORCID: https://orcid.org/0000-0002-0516-0623 \\ Universidade de Cruz Alta, Brasil \\ E-mail: angelakeitel@unicruz.edu.br \\ Vanessa Steigleder Neubauer \\ ORCID: https://orcid.org/0000-0001-6182-3455 \\ Universidade de Cruz Alta, Brasil \\ E-mail: vneubauer@unicruz.edu.br \\ Deivid Jonas Silva da Veiga \\ ORCID: https://orcid.org/0000-0002-1625-0560 \\ Escola Superior do Ministério Público, Brasil \\ E-mail: deividveiga96@gmail.com \\ Aline Antunes Gomes \\ ORCID: https://orcid.org/000-0003-4845-5664 \\ Universidade de Cruz Alta, Brasil \\ E-mail: algomes@unicruz.edu.br \\ Ieda Márcia Donati Linck \\ ORCID: https://orcid.org/0000-0001-5984-4003 \\ Universidade de Cruz Alta, Brasil \\ E-mail: imdlinck@gmail.com
}

\begin{abstract}
Resumo
O presente artigo aborda a (im) possibilidade do reconhecimento da dupla paternidade ou maternidade socioafetivas, em casos onde o terceiro, doador de material genético, está disposto a renunciar seu direito. A questão levantada é se os tribunais brasileiros, ao decidirem apenas pelo reconhecimento da família socioafetiva, constituída por dois pais ou duas mães, nos casos de gestações com multiplicidade de vínculos parentais em face de doação de material genético por terceiro, levam em consideração o princípio do melhor interesse da criança ou adolescente. Assim, necessário, portanto, fazer uma análise acerca dos posicionamentos firmados pelos tribunais brasileiros. O artigo científico desenvolveu-se a partir do método qualitativo, mediante revisão doutrinária e jurisprudencial, bem como levantamento bibliográfico em revistas e artigos científicos. O método de pesquisa foi o hipotético-dedutivo. A pesquisa apresenta um breve estudo sobre o instituto do direito de família, sendo posteriormente tratado acerca da paternidade e maternidade sociafetiva, finalizando com a análise do posicionamento adotado pelos tribunais brasileiros no que diz respeito aos casos de gestações com multiplicidade de vínculos. Como resultado deste trabalho foi possível verificar que o posicionamento que começa a se difundir pelos tribunais brasileiros, nos casos de doação de material genético por terceiro e que não tem interesse em participar da vida da criança é no sentido favorável, ou seja, da possibilidade de haver apenas o reconhecimento da dupla paternidade ou maternidade socioafetivas em prol do superior interesse da criança.
\end{abstract}

Palavras-chave: Multiparentalidade; Criança; Possibilidade; Reconhecimento; Socioafetividade.

\begin{abstract}
This article addresses the (im) possibility of acknowledging dual socio-affective paternity and maternity, in cases where the third party, a genetic material donor, is willing to waive his right. The question raised is whether the Brazilian courts, when deciding only for the recognition of the socio-affective family, consisting of two fathers or two mothers, in cases of pregnancies with multiple parental ties due to the donation of genetic material by a third party, take into account the principle in the best interest of the child or adolescent. Therefore, it is necessary, therefore, to make an analysis of the positions established by the Brazilian courts. The scientific article was developed from the qualitative method, through a doctrinal and jurisprudential review, as well as a bibliographic survey in journals and scientific articles. The research method was hypothetical-deductive. The research presents a brief study on the institute of family law, which is later dealt with social paternity and maternity, ending with the analysis of the position
\end{abstract}


adopted by Brazilian courts with regard to cases of pregnancies with multiple ties. As a result of this work, it was possible to verify that the position that begins to spread by the Brazilian courts, in cases of donation of genetic material by a third party and who has no interest in participating in the child's life, is in a favorable sense, that is, the possibility of there is only recognition of dual socio-affective paternity and maternity in favor of the child's best interests.

Keywords: Multiparenting; Child; Possibility; Recognition; Socio-affectivity.

\section{Resumen}

Este artículo aborda la (im) posibilidad de reconocer la dual paternidad y maternidad socioafectiva, en los casos en que el tercero, donante de material genético, esté dispuesto a renunciar a su derecho. La pregunta que se plantea es si los tribunales brasileños, al decidir únicamente por el reconocimiento de la familia socioafectiva, formada por dos padres o dos madres, en casos de embarazos con múltiples vínculos parentales por donación de material genético por parte de un tercero, tener en cuenta el principio del interés superior del niño, niña o adolescente. Por tanto, es necesario, por tanto, hacer un análisis de las posiciones establecidas por los tribunales brasileños. El artículo científico se desarrolló a partir del método cualitativo, mediante una revisión doctrinal y jurisprudencial, así como un relevamiento bibliográfico en revistas y artículos científicos. El método de investigación fue hipotético-deductivo. La investigación presenta un breve estudio sobre el instituto de derecho de familia, que luego se trata de la paternidad social y la maternidad, finalizando con el análisis de la posición adoptada por los tribunales brasileños con respecto a los casos de embarazos con múltiples vínculos. Como resultado de este trabajo, se pudo constatar que la posición que comienza a difundir por los tribunales brasileños, en casos de donación de material genético por un tercero y que no tiene interés en participar en la vida del niño, es de una sentido favorable, es decir, la posibilidad de que sólo se reconozca la dual paternidad y maternidad socioafectiva a favor del interés superior del niño.

Palabras clave: Multiparenting; Niño; Posibilidad; Reconocimiento; Socio-afectividad.

\section{Introdução}

Inicialmente, cabe destacar que, foi com a Constituição Federal de 1988 que a distinção entre filhos legítimos, legitimados e ilegítimos apartou-se do sistema do Código Civil de 1916, cujo paradigma em matéria de filiação adotava a presunção baseada na centralidade do casamento e desconsiderava tanto o critério biológico, quanto o afetivo. Atualmente, o conceito clássico de família não atende mais à sociedade e suas complexas relações, de forma que as entidades familiares têm se pautado para além dos laços biológicos, fazendo com que o conceito de afeto torne-se cada vez mais presente nas famílias contemporâneas.

Embora não esteja expressamente prevista na legislação brasileira, nota-se que a afetividade tornou-se um princípio no sistema jurídico. A partir da mudança na forma como as relações sociais e familiares estão se constituindo, é possível perceber um aumento no que diz respeito à afetividade, pois a entidade familiar não se restringe mais a união entre homem e mulher, tampouco aos descendentes advindos do casamento. Atualmente, o vínculo biológico não é o meio exclusivo para a criação e existência de laços, tornando-se a afetividade cada vez mais forte nas relações e interações sociais. Ademais, o princípio da afetividade pauta o reconhecimento socioafetivo, que ocorre voluntariamente entre as partes que decidem oficializar o vínculo constituído pelo afeto. Através do reconhecimento da socioafetividade há a possibilidade de inclusão do nome do pai ou mãe socioafetivo no registro civil.

Nestes casos, há tanto a opção de exclusão do genitor biológico do registro civil, como a possiblidade de mantê-lo, o que acarretaria na multiparentalidade. Neste passo, o Supremo Tribunal Federal (STF), em sede de repercussão geral $n^{\circ} 622$, decidiu que a paternidade socioafetiva não exime de responsabilidade biológica. Dessa forma, a filiação não mais se baseia nos antigos moldes familiares patriarcais, pelo contrário, busca-se cada vez mais oportunizar ao indivíduo uma potencialização da entidade familiar, de forma a reconhecer os elos afetivos e proteger o princípio do melhor interesse da criança que busca pelo reconhecimento socioafetivo, muitas vezes sem desprezar o biológico.

Contudo, o presente artigo delimita-se à análise do reconhecimento da paternidade ou maternidade socioafetiva em que há um(a) genitor(a) biológico(a) que não tem interesse em constar no registro civil do descendente, bem como não possui interesse em participar da vida da criança, visto ser meramente doador do material genético, além disso por já existir uma entidade familiar consolidada através do vínculo afetivo. 
O objetivo geral da pesquisa é verificar se os tribunais estão levando em consideração o princípio do melhor interesse da criança e do adolescente ao reconhecer apenas a dupla paternidade ou maternidade socioafetiva nos casos de multiplicidade de vínculos parentais, haja vista a renúncia do doador do material genético em participar da vida da criança.

Deste modo, apresenta-se o seguinte questionamento: os tribunais estão levando em consideração o princípio do melhor interesse da criança ao decidirem apenas pelo reconhecimento da família socioafetiva, constituída por dois pais ou duas mães, nos casos de gestações com multiplicidade de vínculos parentais em face de doação de material genético por terceiro?

Nesse sentido, a resposta para a indagação desta pesquisa compreende na tendência dos Tribunais em decidir favoravelmente nos casos de manifestação do(a) genitor(a) biológico(a), que tem o papel meramente de doador genético, bem como nas gestação por substituição, além do fato de haver renúncia sobre esse direito. Portanto, pressupõe-se que para atender ao princípio do melhor interesse, nos casos em que as famílias já estão constituídas pelos laços do afeto e em havendo multiplicidade parentais, haverá a possibilidade do reconhecimento da filiação ocorrer somente através da paternidade ou maternidade socioafetiva em detrimento da paternidade biológica, haja vista o não interesse deste em participar da vida da criança, ou seja, por ter sido sua participação apenas no intuito de contribuir com o material genético.

Ademais, a pesquisa foi dividida em três seções, sendo que a primeira versou sobre o instituto familiar e sua transformação ao longo do tempo, a segunda tratou sobre a Paternidade Socioafetiva e as novas perspectivas para os arranjos familiares atuais, e por fim, a terceira seção abordou acerca da análise do entendimento jurisprudencial através da compreensão acerca da paternidade biológica e afetiva analisando sobre a (im) possibilidade de ocorrer o reconhecimento concomitante das filiações biológica e socioafetiva.

\section{Metodologia}

A presente pesquisa obteve seu desenvolvimento a partir da abordagem qualitativo. Sabe-se que as pesquisas realizadas sob a vista qualitativa possuem métodos interpretativos subjetivos, cujo objetivo é o entendimento de aspectos que envolvem a formação histórica da sociedade como ações, valores, crenças e características intrinsecas ao meio social (Minayo, 1983, p. 239-262).

O método abordado foi o hipotético-dedutivo, também conhecido como "método de tentativas e eliminação de erros" (Popper, 1975), é um metodo que busca dirimir as questões levantadas mediante a formulação de hipóteses ou teorias, o qual já possui por intuito corrigir possíveis erros a surgir frente ao questionamento levantado.

Realizou-se, também, uma revisão por meio de levantamento bibliográfico, utilizando-se doutrinas, artigos científicos e jurisprudências existentes sobre o assunto. Destacam-se alguns autores que foram utilizados para o embasamento desta pesquisa: Maria Berenice Dias, Rolf Madaleno, Carlos Roberto Gonçalves e Cario Mario da Silva Pereira, dentre outros.

\section{Resultados e Discussão}

\subsection{O instituto familiar e sua transformação ao longo do tempo}

A família patriarcal tradicionalmente conhecida, constituída por pai, mãe e os filhos que resultam dessa união, por muito tempo foi difundida e socialmente aceita como a única forma de instituição familiar. No entanto, o conceito de família está mais abrangente e inclusivo, ainda que haja certa resistência por parte da sociedade em aceitar os novos arranjos. Para Pereira (2018, p. 44),

Desapareceu a organização patriarcal, que vigorou no Brasil por todo o Século XX, não apenas no direito, mas, sobretudo, nos costumes. O pai, como um pater romano, exercia autoridade plena sobre os filhos, que nada faziam sem a sua permissão. Escolhia-lhes a profissão, elegia o noivo da filha, estava presente em toda a vida de uns e de outros, a cada momento. 
O instituto familiar fundou-se sob aspectos muito rigorosos, ditados, principalmente, pela esfera religiosa e por preceitos morais extremamente rígidos, o que limitou por séculos a maneira como as pessoas se relacionavam dentro do núcleo familiar. As formas de interação entre as famílias eram basicamente as mesmas, sendo o homem a figura que provia e protegia os demais membros da família, com uma posição pautada no autoritarismo e machismo, de forma que, para a mulher, restava realizar as tarefas domésticas, desenvolvendo um papel de submissão junto com os filhos, que não tinham suas individualidades respeitadas. Assim corrobora Madaleno (2018, p. 34),

A mulher era totalmente subordinada à autoridade marital e podia ser repudiada por ato unilateral do marido. $\mathrm{O}$ pater exercia a sua autoridade sobre todos os seus descendentes não emancipados, sobre a sua esposa e as mulheres casadas com manus com os seus descendentes. A família era, então, simultaneamente, uma unidade econômica, religiosa, política e jurisdicional. $\mathrm{O}$ ascendente comum vivo mais velho era, ao mesmo tempo, chefe político, sacerdote e juiz.

Estes ditames, através da evolução da sociedade, começaram aos poucos a serem desconstruídos e deram espaço a uma forma de interação familiar mais democrática. A Declaração Universal dos Direitos Humanos, em seu artigo $16^{\circ}$, conceitua a família como o elemento natural e fundamental da sociedade e que tem direito à proteção desta e do Estado, sendo de extrema importância a criação de leis que respaldam uma construção familiar pautada na igualdade entre os membros familiares e não mais no autoritarismo paterno (Assembleia Geral da ONU, 1948).

Verifica-se que a concepção de família, rígida e envolvida por tabus, deixa aos poucos o aprisionamento a diversos estigmas e amplia-se cada vez mais para atender as demandas sociais oriundas da expansão dos arranjos familiares. Assim, conforme a sociedade evolui, os comportamentos sociais também se modificam, o que leva a uma mudança não apenas no aspecto social, mas também no âmbito jurídico, o que enseja em adequações que abranjam essas transformações (Abrantes Neto, Melo, \& Santos, 2020).

A necessidade de readequar a visão sobre o conceito de família expandiu-se para além do âmbito social e partiu para uma mudança legislativa, uma vez que as novas formas de convivência familiar necessitavam de um respaldo jurídico. O Código Civil de 1916, o primeiro a vigorar no Brasil, no que refere ao direito de família, tinha como principais funções proteger o patrimônio e interesses do homem, sendo as demais demandas deixadas em segundo plano, inclusive os direitos correspondentes às mulheres, que praticamente inexistiam. Fundamentado pela "fumaça do machismo", o Código Civil de 1916 contava com artigos que deixavam explícitas a sua função. Neste sentido, aduz Barreto (2013, p. 209):

Àquela época, a família patriarcal posicionava-se como coluna central da legislação e prova disso foi a indissolubilidade do casamento, como também a capacidade relativa da mulher. O artigo 233 do Código Civil de 1916 designava o marido como único chefe da sociedade conjugal. Além disso, à mulher era atribuída somente a função de colaboradora dos encargos familiares, consoante artigo 240 do mesmo diploma legal.

A distinção não ocorria apenas entre o papel do homem e da mulher, ocorria também quando a questão era pertinente aos filhos, não sendo aceitos filhos concebidos fora do casamento, que ficavam sem amparo legal algum, bem como os filhos adotivos. Nesta linha, Barreto (2013, p. 209-210) menciona que,

No que concerne à filiação, havia notória distinção entre os filhos legítimos e ilegítimos, naturais e adotivos, que era devidamente registrada no assento de nascimento a origem da filiação. Quanto aos bens, conforme o artigo 377 deste Código: "quando o adotante tiver filhos legítimos, legitimados ou reconhecidos, a relação de adoção não envolve a de sucessão hereditária".

Nesta senda, a Constituição Federal de 1988 foi um importante marco legal, pois tirou o estigma de que o único meio de se constituir uma família era através do matrimônio. Inúmeras pessoas viviam à margem do seu núcleo familiar pois eram frutos de uniões que não se encaixavam no que era social e juridicamente aceito. O direito de família, à luz da Constituição 
Federal de 1988, foi elencado no artigo $226^{1}$ e a partir dele é possível extrair a ideia de que a família é o núcleo no qual o indivíduo desenvolve-se, primando pelo princípio da dignidade da pessoa humana. Pode-se dizer então que, a Constituição Federal ampliou e trouxe à baila um sentido mais abrangente e igualitário do significado de família.

Neste seguimento, Dias (2016, p. 57) diz que "em face da nova tábua de valores da Constituição Federal, ocorreu a universalização e a humanização do direito das famílias, que acabou por provocar um câmbio de paradigmas". Com a promulgação da Constituição da República Federativa do Brasil, houve uma mudança significativa na forma como o Direito de Família era estabelecido. Verificou-se um amparo mais efetivo das garantias e direitos dos indivíduos.

Imperioso ressaltar que outra importante transformação ocorreu no sentido de instituir às crianças e adolescentes a garantia de seus direitos, o que aparece na forma do princípio do melhor interesse da criança. Mencionado princípio está implícito na Doutrina da Proteção Integral, no artigo 227 da Constituição Federal e diz que:

Art. 227. É dever da família, da sociedade e do Estado assegurar à criança, ao adolescente e ao jovem, com absoluta prioridade, o direito à vida, à saúde, à alimentação, à educação, ao lazer, à profissionalização, à cultura, à dignidade, ao respeito, à liberdade e à convivência familiar e comunitária, além de colocá-los a salvo de toda forma de negligência, discriminação, exploração, violência, crueldade e opressão.

Os artigos $3^{2}, 4^{3}$ e $5^{4}$ do Estatuto da Criança e do Adolescente discorrem sobre o princípio do melhor interesse da criança e do adolescente. Nota-se que os artigos supra não estabelecem em que regime familiar as crianças devem viver, eles apenas estabelecem os direitos das crianças e dos adolescentes e os deveres dos seus responsáveis, devendo ser analisado cada caso individualmente para que seja possível definir e resguardar o que for do melhor interesse dos menores, conforme analisa Machado (2003, p. 146):

Não há mais uma dualidade no ordenamento jurídico envolvendo a coletividade crianças e adolescentes ou a categoria crianças e adolescentes: a categoria é uma e detentora do mesmo conjunto de direitos fundamentais; o que não impede, nem impediu, o ordenamento de reconhecer situações jurídicas específicas e criar instrumentos para o tratamento delas, como aliás, ocorre em qualquer ramo do direito.

Um dos marcos foi não mais atrelar a família unicamente ao conceito matrimonial, bem como a queda da distinção entre os filhos legítimos, os concebidos fora do casamento e os adotados, passando todos a gozarem dos mesmos direitos. Estabeleceu-se assim um novo começo para o Direito de Família e uma nova maneira de olhar para ele. Denota-se que o

\footnotetext{
${ }^{1}$ Art. 226. Família, base da sociedade, tem especial proteção do Estado. $\S 1^{\circ} \mathrm{O}$ casamento é civil e gratuita a celebração. §2O casamento religioso tem efeito civil, nos termos da lei. $\S 3^{\circ}$ Para efeito da proteção do Estado, é reconhecida a união estável entre o homem e a mulher como entidade familiar, devendo a lei facilitar sua conversão em casamento.\$4 Entende-se, também, como entidade familiar a comunidade formada por qualquer dos pais e seus descendentes. $\$ 5$ Os direitos e deveres referentes à sociedade conjugal são exercidos igualmente pelo homem e pela mulher.\$6 O casamento civil pode ser dissolvido pelo divórcio.\$ $7^{\circ}$ Fundado nos princípios da dignidade da pessoa humana e da paternidade responsável, o planejamento familiar é livre decisão do casal, competindo ao Estado propiciar recursos educacionais e científicos para o exercício desse direito, vedada qualquer forma coercitiva por parte de instituições oficiais ou privadas. $\$ 8^{\circ} \mathrm{O}$ Estado assegurará a assistência à família na pessoa de cada um dos que a integram, criando mecanismos para coibir a violência no âmbito de suas relações.

${ }^{2}$ Art. $3^{\circ} \mathrm{A}$ criança e o adolescente gozam de todos os direitos fundamentais inerentes à pessoa humana, sem prejuízo da proteção integral de que trata esta Lei, assegurando-se-lhes, por lei ou por outros meios, todas as oportunidades e facilidades, a fim de lhes facultar o desenvolvimento físico, mental, moral, espiritual e social, em condições de liberdade e de dignidade.

${ }^{3}$ Art. $4^{\circ}$ É dever da família, da comunidade, da sociedade em geral e do poder público assegurar, com absoluta prioridade, a efetivação dos direitos referentes à vida, à saúde, à alimentação, à educação, ao esporte, ao lazer, à profissionalização, à cultura, à dignidade, ao respeito, à liberdade e à convivência familiar e comunitária.

${ }^{4}$ Art. $5^{\circ}$ Nenhuma criança ou adolescente será objeto de qualquer forma de negligência, discriminação, exploração, violência, crueldade e opressão, punido na forma da lei qualquer atentado, por ação ou omissão, aos seus direitos fundamentais.
} 
conceito de família expandiu-se com o passar dos anos, uma vez que as formas de interações sociais estão em constante transformação, o que ensejou uma mudança para tentar abranger e incluir os novos arranjos familiares.

Essas transformações ocorreram de maneira que, atualmente, é possível enumerar uma quantidade considerável de entidades familiares, que surgem das mais diferentes formas. Dentre os modelos familiares que surgiram, grande parte já tem reconhecimento doutrinário e cada vez mais, é legalmente amparado. Em que pese o reconhecimento da instituição familiar fosse restrito à família matrimonial patriarcal, aos poucos esse conceito foi cedendo e abrindo espaço para o reconhecimento da união estável e da família monoparental. Urge mencionar que a ampliação do reconhecimento dos novos arranjos perpassam antigas barreiras fundadas tanto no preconceito, quanta na intolerância. A Constituição Federal de 1988 foi um dos marcos para que isto fosse possível. Dessa maneira, a Constituição Federal de 1988, de acordo com Dias (2016, p. 52),

Instaurou a igualdade entre o homem e a mulher e esgarçou o conceito de família, passando a proteger de forma igualitária todos os seus membros. Estendeu proteção à família constituída pelo casamento, bem como à união estável entre o homem e a mulher e à comunidade formada por qualquer dos pais e seus descendentes, que recebeu o nome de família monoparental. Consagrou a igualdade dos filhos, havidos ou não do casamento, ou por adoção, garantindolhes os mesmos direitos e qualificações.

Destarte, o modo como o direito passou a olhar as novas instituições familiares sofreu modificações quanto a sua abrangência, visto que, diante de o surgimento das novas famílias, foi necessário ampliar, também, a normativa e a legislação. Se antes a família matrimonial era o único meio de, legalmente, constituir uma família, hoje não é mais. A união estável é um exemplo de constituição familiar que não era reconhecida e hoje possui tanta validade quanto o casamento. Madaleno (2018, p.47) refere que, "com o passar dos tempos e a evolução dos costumes sociais, a união estável foi posta constitucionalmente ao lado da família do casamento, a merecer a proteção do Estado e figurar como essencial à estrutura social.

A família monoparental também foi abarcada pela Constituição Federal de 1988. Assim, refere Dias (2016, p. 241),

A Constituição, ao esgarçar o conceito de família, elencou como entidade familiar a comunidade formada por qualquer dos pais e seus descendentes (CF $226 \S 44^{\circ}$ ). O enlaçamento dos vínculos familiares constituídos por um dos genitores com seus filhos, no âmbito da especial proteção do Estado, subtrai a conotação de natureza sexual do conceito de família. Tais entidades familiares receberam em sede doutrinária o nome de família monoparental, como forma de ressaltar a presença de somente um dos pais na titularidade do vínculo familiar.

Desse modo, são três os modelos de famílias explicitamente elencadas pela Constituição Federal: a família matrimonial, presente no artigo $226 \S 1^{\circ} \mathrm{e} \S 2^{\circ}$, da Constituição Federal; a união estável, que consta no art. $226 \S 3^{\circ}$ e família monoparental, que está disposta no artigo $226 \S 4^{\circ}$, CF. Alguns outros modelos familiares são amparados pela doutrina, como é o caso da eudemonista, que concentra-se na busca do amor, felicidade e realização de todos os seus membros (Dias, 2016) ou a família homoafetiva, cujo enlace se dá com a união de duas pessoas do mesmo sexo, embora fora rechaçada e excluída o Código Civil, já encontra, além de maior aceitação social, amparo nos tribunais e na Lei Maria da Penha. Tanto para responder a questões de filiação, quanto para resolver questões hereditárias. Neste sentido, Dias (2016, p. 462), menciona que,

Ainda que não haja expressa referência às uniões homoafetivas, não há como deixá-las fora do atual conceito de família. Passando duas pessoas ligadas por um vínculo afetivo a manter relação duradoura, pública e contínua, como se casadas fossem, formam um núcleo familiar, independentemente do sexo a que pertencem. A única diferença que essa convivência guarda com a união estável entre um homem e uma mulher é a inexistência da possibilidade de gerar filhos. Tal circunstância, por óbvio, não serve de fundamento para qualquer diferenciação, por não ser requisito para o reconhecimento da entidade familiar. 
Além da Constituição Federal, o Estatuto da Criança e do Adolescente (ECA), em seu artigo $25^{5}$, reconhece três tipos de família, sendo elas, a família natural, a família extensa e a família substituta. O ECA conceitua a família natural como “comunidade formada pelos pais ou qualquer deles e seus descendentes.”. No caso da família extensa, Dias (2016, p.246) destaca que "este conceito dispõe de um pressuposto além do elo consanguíneo. A lei exige que já exista um vínculo de convivência, afinidade e afetividade da criança com algum parente como família extensa.”, enquanto a família substituta é utilizada como último recurso, pois há preferência para reinserção na família biológica ou extensa. Analisa Dias (2016, p. 247), que o Estatuto da Criança e do Adolescente não designou o que é a família substitua, o que leva a conclusão de que, nesse caso, são as famílias no cadastro de adoção.

Nota-se que os novos arranjos familiares são pautados para além dos laços sanguíneos e biológicos, usando a afetividade como novo meio de constituir uma família. Nessa linha, Dias (2016, p. 211-212) corrobora destacando:

Cada vez mais a verdade biológica e a verdade registral cedem frente a realidade da vida, que privilegia os vínculos da afetividade como geradores de direitos e de obrigações. Daí a consagração da filiação socioafetiva, que tem origem não em um ato - como a 211/1276 concepção ou o registro - mas em um fato: a convivência que faz gerar o que se chama de posse de estado de filho.

A família denominada como recomposta ou mosaico foi uma das primeiras expressões e manifestações da socioafetiva, uma vez que ela se dá a partir da união de um casal que já possui filhos de uma relação prévias, o que, muitas vezes, resulta na constituição da filiação socioafetiva. Descreve, Madaleno (2018 p. 51):

Com a disseminação dos divórcios e até mesmo das dissoluções das inúmeras uniões estáveis vão surgindo as figuras dos padrastos e das madrastas, dos enteados e das enteadas, e que ocupam os papéis domésticos dos pais e mães, dos filhos e das filhas e dos meio-irmãos que são afastados de uma convivência familiar e que passam a integrar uma nova relação familiar proveniente dos vínculos que se formam entre um dos membros do casal e os filhos do outro.

A socioafetividade, estendeu-se, também, às famílias homoafetivas, que enfrentaram dificuldades até obter o devido reconhecimento, mas que acabou por ser legalmente reconhecido amparada, conforme explana Madaleno (2018, p. 70):

Alenta poder reconhecer, finalmente, que a união homoafetiva também se torna destinatária das consequências jurídicas tradicionalmente atribuídas aos parceiros heteroafetivos e tal afirmação entoa absolutamente serena diante do histórico julgamento conjunto, pelo Supremo Tribunal Federal, da ADPF 132/2008 (Ação de Descumprimento de Preceito Fundamental) e da ADI 4.277/2009 (Ação Direta de Inconstitucionalidade).

Assim, percebe-se a evolução no instituto familiar, visto a existência de novos arranjos e novas formas de interações familiares, culminando em adaptações jurídicas e sociais, como a paternidade socioafetiva, que será abordada na seção seguinte.

\subsection{Paternidade Socioafetiva: Novas perspectivas para os arranjos familiares atuais}

Os arranjos familiares estão mais diversos e contemplam as diferentes formas de interações familiares, como explicitado anteriormente, visto que em uma sociedade cada vez mais plural, a paternidade ou maternidade socioafetiva surge como uma opção para as famílias que já viviam e identificavam-se com esse tipo de relação, porém sem o devido reconhecimento, pois em alguns casos o enlace formal ocorre apenas post mortem, o que se dá devido à recente possibilidade

\footnotetext{
${ }^{5}$ Art. 25. Entende-se por família natural a comunidade formada pelos pais ou qualquer deles e seus descendentes. Parágrafo único. Entende-se por família extensa ou ampliada aquela que se estende para além da unidade pais e filhos ou da unidade do casal, formada por parentes próximos com os quais a criança ou adolescente convive e mantém vínculos de afinidade e afetividade.
} 
de haver esse reconhecimento de forma mais abrangente. Neste sentido, cabe mencionar a jurisprudência do Tribunal de Justiça do Rio Grande do Sul, a qual reconheceu a paternidade socioafetiva post mortem:

APELAÇÃO CÍVEL. AÇÃO DE RECONHECIMENTO DE PATERNIDADE SOCIOAFETIVA POST MORTEM. POSSE DE ESTADO DE FILHO. COMPROVAÇÃO. GRATUIDADE DE JUDICIÁRIA. CONCESSÃO. 1. Irretocável a sentença fustigada, que julgou procedente o pedido de reconhecimento de paternidade socioafetiva post mortem, na medida em que demonstrada a presença dos respectivos elementos caracterizadores, quais sejam, nome, trato e fama. 2. Tendo a parte apelante comprovado a insuficiência de recursos para suportar os valores das despesas do processo, estão satisfeitos os requisitos para a concessão do benefício da assistência judiciária gratuita. APELAÇÃO PARCIALMENTE PROVIDA. (Apelação Cível, No 70081940447, Oitava Câmara Cível, Tribunal de Justiça do RS, Relator: Ricardo Moreira Lins Pastl, Julgado em: 26-09-2019).

Da mesma forma, a $1^{\mathrm{a}}$ Câmara de Direito Privado julgou favoravelmente o pedido de reconhecimento da maternidade socioafetiva, preservando a maternidade:

MATERNIDADE SOCIOAFETIVA Preservação da Maternidade Biológica Respeito à memória da mãe biológica, falecida em decorrência do parto, e de sua família - Enteado criado como filho desde dois anos de idade Filiação socioafetiva que tem amparo no art. 1.593 do Código Civil e decorre da posse do estado de filho, fruto de longa e estável convivência, aliado ao afeto e considerações mútuos, e sua manifestação pública, de forma a não deixar dúvida, a quem não conhece, de que se trata de parentes - A formação da família moderna não-consanguínea tem sua base na afetividade e nos princípios da dignidade da pessoa humana e da solidariedade Recurso provido. (TJ-SP APL: 64222620118260286 SP 0006422-26.2011.8.26.0286, Relator: Alcides Leopoldo e Silva Júnior; Data de Julgamento: 14/08/2012, $1^{\text {a }}$ Câmara de Direito Privado, Data de Publicação: 14/08/2012).

Nota-se que a família patriarcal baseada em contratos e costumes perdeu considerável espaço e deixou de ser a única e mais valorizada forma de constituição familiar. Os laços afetivos pautados no respeito, amor e afeto tomaram e estão tomando cada vez mais lugar no mundo jurídico e sua efetividade como forma de reconhecimento da parentalidade está sendo valorizada pelo direito. Nesta linha, Madaleno (2018, p. 66):

Prepondera o princípio constitucional da afetividade, sobrepondo o afeto sobre o aspecto patrimonial e econômico que antigamente identificava a família exclusiva do casamento. Passando a mulher a assumir uma carreira profissional e contribuindo para a subsistência doméstica, extrapolando os limites domésticos de sua atuação, os elos afetivos cuidaram de estruturar a nova família que encontra sua dignidade e realização pessoal de cada integrante do núcleo familiar.

Ainda na esfera constitucional, de acordo com Lobo (2003, p. 42-43).

a) Todos os filhos são iguais, independentemente de sua origem (art. 227, § $6^{\circ}$ );

b) a adoção, como escolha afetiva, alçou-se integralmente ao plano da igualdade de direitos ( $\operatorname{art} .227, \S \S 5^{\circ}$ e $6^{\circ}$ );

c) a comunidade formada por qualquer dos pais e seus descendentes, incluindo-se os adotivos, tem a mesma dignidade da família constitucionalmente protegida (art. 226, $\S 4^{\circ}$ );

d) o direito à convivência familiar, e não a origem genética, constitui prioridade absoluta da criança e do adolescente (art. 227, caput).

Percebe-se que os vínculos que caracterizam a filiação não são apenas de ordem biológica e então, urge observar que, para além disso, há outros fatores que influenciam diretamente na formação de uma família, dentre eles o amor, o afeto, a identificação com outro, liberdade e o respeito. Esses são os princípios basilares de uma família que se constitui não necessariamente pelos vínculos biológicos, mas também pelos laços afetivos.

Deste modo, o instituto familiar passou a formar-se não mais pelo vínculo unicamente matrimonial e com o intuito de procriação e fortalecimento patrimonial, mas sim dando espaço para novas manifestações do relacionamento humano que desenvolveu-se naturalmente com o passar dos anos. A primazia do vínculo biológico foi, aos poucos, dando espaço a novas formas de interações no âmbito familiar, uma vez que não é incomum, os filhos serem vítimas de abandono por parte dos pais biológicos e serem acolhidos por outras pessoas que desenvolvem essa função. Denota-se que uma dessas manifestações é o 
afeto, que serve como base para as mais diversas formas de constituições familiares que hoje existem e pautam-se acima de tudo no respeito, amor e afeição mútua.

Os vínculos afetivos tornaram-se tão relevantes quanto os biológicos, ampliando e ressignificando a filiação. Dias (2016, p. 678) discorre sobre isso quando fundamenta que filiação socioafetiva assenta-se no reconhecimento da posse de estado de filho: a crença da condição de filho fundada em laços de afeto.

Observa-se que, a filiação socioafetiva ocorre no momento em que o pai ou mãe afetivo interagem com o filho de forma que suprem todas as necessidades que ele demanda, sejam elas de cunho intelectual, afetivo ou psicológico. A partir disto, quando se constitui um vínculo de parentalidade, que parte do princípio da afetividade, é possível haver o reconhecimento jurídico desse estado.

De outra banda, a afetividade não surge para excluir os vínculos biológicos e sanguíneos, contudo há casos em que o vínculo afetivo prepondera, haja vista a relação de convivência e a ausência do convívio com o genitor biológico. Entretanto, identifica-se a possibilidade de o vínculo biológico coexistir com o vínculo afetivo, surgindo então, a possibilidade da multiparentalidade. Para Gonçalves (2017, p. 398), "a multiparentalidade, pois, consiste no fato de o filho possuir dois pais ou mães reconhecidos pelo direito, o biológico e o socioafetivo, em função da valorização da filiação socioafetiva".

Assim, com a finalidade de regulamentar esse aspecto do Direito de Família, o Provimento 63/2017 do Conselho Nacional de Justiça, permitiu o reconhecimento da paternidade socioafetiva voluntária extrajudicial perante os oficiais de registro civil de pessoas naturais, o que anteriormente ocorria apenas através da intervenção do Poder Judiciário. Na Seção II do Provimento estão elencados os requisitos que regem os termos em que pode ser efetivado o registro da paternidade ou maternidade socioafetiva e nos casos em que não há o cumprimento dos requisitos, as partes devem buscar o reconhecimento perante o Poder Judiciário. Esta medida foi fundamental para que houvesse a facilitação do reconhecimento de muitas famílias que já viviam dessa maneira, porém sem o devido reconhecimento jurídico.

Neste contexto, foi levantada uma questão pertinente ao assunto, a multipentalidade, elencada no artigo $14^{6}$ do Provimento 63/2017. Pautada no texto do artigo houve dúvidas relativas a expressão "unilateral", da qual Tartuce (2018, [s. p]) discorre,

Duas correntes se formaram nos principais fóruns de debates do seu conteúdo. Uma mais cética, à qual estava filiado, entendia que a norma não reconhecia a multiparentalidade pela via extrajudicial, diante do uso do termo "unilateral", o que supostamente atingia o vínculo em relação ao ascendente reconhecedor. A outra, mais otimista, concluía de forma contrária, ou seja, na linha de efetivação extrajudicial completa da decisão do STF.

Quanto a isto, a Associação Nacional dos Registradores de Pessoas Naturais (ARPEN) manifestou-se acerca do reconhecimento da multiparentalidade:

Dessa forma, as pessoas que já possuem pai e mãe registral, para terem reconhecimento de um pai e uma mãe sociafetivo, formando a multiparentalidade, deverá o registrador civil realizar dois atos, um para o pai socioafetivo e outro para a mãe socioafetiva.

Nesta senda, o reconhecimento sociafetivo não exclui o reconhecimento da filiação biológica, visto que a multiparentalidade, consiste no fato de o filho possuir dois pais ou mães reconhecidos pelo direito, o biológico e o socioafetivo, em função da valorização da filiação socioafetiva. Por isso, o reconhecimento deve ser pautado na responsabilidade, visto que envolve sempre uma criança ou adolescente e o princípio do melhor interesse deve ser sempre

\footnotetext{
${ }^{6}$ Art. 14. O reconhecimento da paternidade ou maternidade socioafetiva somente poderá ser realizado de forma unilateral e não implicará o registro de mais de dois pais e de duas mães no campo FILIAÇão no assento de nascimento.
} 
observado para evitar casos em que o pai registral postule a anulação do registro, como o analisado no REsp. 932692, publicado no Diário da Justiça no dia 12.02.2009:

a) prevalência dos interesses da criança ("possibilidade de uma criança ser desamparada por um ser adulto que a ela não se ligou, verdadeiramente, pelos laços afetivos"); b) preservação do estado de filiação; c) o reconhecimento espontâneo da paternidade pelo registro não pode ser considerado vício de consentimento ("o próprio pai manifestou que sabia perfeitamente não haver vínculo biológico entre ele e o menor e, mesmo assim, reconheceu-o como seu filho"); d) o pai registral, que se volta contra o registro, age com venire contra factum proprium ("utilização da própria torpeza para benefício próprio").

Assim, observa-se que, através da paternidade ou maternidade socioafetiva se oficializa o reconhecimento dos novos arranjos familiares, sendo necessário que esse reconhecimento seja responsável a fim de evitar maiores dissabores à criança ou adolescente. Todavia, outras questões surgem em meio a filiação sociafetiva que emergem de novas possibilidades de se constituir uma família. Sob essa análise aporta o caso da união homoafetiva, em que o casal para ter um filho precisa buscar outros meios, que podem ser através da adoção e a inseminação artificial, por exemplo.

Diante desse cenário, percebe-se a importância do reconhecimento dessas novas configurações familiares através da paternidade ou maternidade socioafetiva. Assim, na próxima seção será analisado como os tribunais tem se posicionado a respeito do assunto.

\subsection{Análise do posicionamento jurisprudencial acerca da paternidade biológica e afetiva e a (im)possibilidade do reconhecimento concomitante das filiações biológica e socioafetiva}

A paternidade socioafetiva vem sendo reconhecida pelos tribunais há algum tempo, contudo é importante ressaltar que outras questões surgem em meio a esse tipo de filiação, questões essas que emergem das novas possibilidades de se constituir uma família. Nota-se que o número de famílias que procuram outras formas de concepção vem aumentando, o que implica em novos desdobramentos, tanto na parte registral da criança, quanto nas consequências jurídicas dessa ação. Assim, verificou-se uma lacuna na legislação, que não versa sobre um tipo específico de formação familiar. Sob essa análise, aporta-se o caso da união homoafetiva, em que o casal para ter um filho precisa buscar outros meios de concepção, que podem ser através da adoção e da inseminação artificial, por exemplo.

Nesse sentido, algumas decisões já foram julgadas, como no caso do casal homoafetivo que vivia em união estável desde 2011 e por meio de inseminação artificial, houve a gravidez por substituição, feita pela irmã de um dos homens. Nesse caso a irmã deixou claro que a gravidez tinha o cunho exclusivo de colaborar com a vontade do irmão de constituir uma família com seu companheiro, tendo ela aberto mãe de registrar a criança.

O Tribunal de Justiça de Santa Catarina entendeu que se tratava de um caso de gravidez por substituição e a criança pode ser registrada com o nome somente dos pais, sendo um deles o biológico e o outro, o afetivo. Importante ressaltar que o casal já constituía uma família e que, por conseguinte, a filiação socioafetiva é o resultado dessa constituição. Nos casos em que há filiação sociafetiva, o melhor interesse da criança deve ser preservado, uma vez que os laços biológicos por si só não constituem o vínculo necessário e suficiente para que haja a constituição da família. Nesta situação, a gestante foi tão somente o meio pelo qual a criança foi gerada, sem que houvesse da parte dela a intenção de constar no registro de nascimento. Neste sentido, o Tribunal de Justiça de Santa Catarina:

APELAÇÃO CÍVEL. AÇÃO DECLARATÓRIA DE DUPLA PATERNIDADE. SENTENÇA DE PROCEDÊNCIA. MÉTODO DE REPRODUÇÃO HETERÓLOGA ASSISTIDA QUE UTILIZOU GAMETA DOADO PELA IRMÃ DE UM DOS AUTORES, QUE TAMBÉM GESTOU A CRIANÇA. REGISTRO DE NASCIMENTO DA MENOR CONSTANDO OS NOMES DO CASAL HOMOAFETIVO COMO SEUS PAIS. INSURGÊNCIA DO MINISTÉRIO PÚBLICO. PRETENDIDA NULIDADE DA SENTENÇA, POR INCOMPETÊNCIA DO JUÍZO E 
PORQUE NÃO LHE FORA OPORTUNIZADA A MANIFESTAÇÃO SOBRE O MÉRITO. ALEGAÇÃO DE QUE O FEITO DEVERIA VERSAR SOBRE ADOÇÃO, EM RAZÃO DE O GAMETA NÃO TER SIDO DOADO POR PESSOA ANÔNIMA, O QUE DETERMINARIA A COMPETÊNCIA DA VARA DA INFÂNCIA E JUVENTUDE. INSUBSISTÊNCIA. PARQUET QUE, AO PROCLAMAR A INCOMPETÊNCIA DO JUÍZO, SE MANIFESTOU SOBRE O MÉRITO DA DEMANDA, OPONDO-SE AO PLEITO, TESE ENCAMPADA DEPOIS PELA PROCURADORIA. INEXISTÊNCIA DE ÓBICE LEGAL AO ATENDIMENTO DO PEDIDO. DOADORA DO GAMETA QUE, APÓS O NASCIMENTO DA CRIANÇA, RENUNCIOU AO PODER FAMILIAR. MELHOR INTERESSE DA CRIANÇA QUE DEVE PREPONDERAR SOBRE FORMALIDADES, APARÊNCIAS E PRECONCEITOS. PEDIDO DE ANTECIPAÇÃO DA TUTELA REALIZADO EM CONTRARRAZÕES. IMEDIATA EMISSÃO DA CERTIDÃO DE NASCIMENTO DA INFANTE, QUE SE ENCONTRA, ATÉ O MOMENTO, DESPROVIDA DO REGISTRO. POSSIBILIDADE. REQUISITOS DO ART. 273 DO DIPLOMA PROCESSUAL PREENCHIDOS. RECURSO DESPROVIDO.[...] O fato de a doadora do óvulo, que também gestou a criança, não ser anônima, não representa óbice para o reconhecimento da parentalidade socioafetiva e consequente registro da criança em nome de ambos os pais, notadamente porque decorre de um projeto amplamente idealizado pelo casal e que - a toda evidência, diante da impossibilidade de os gametas de ambos os interessados serem utilizados na fecundação - só pôde ser concretizado mediante a utilização de método de reprodução heteróloga assistida. Formalidades não essenciais, aparências e preconceitos não podem preponderar sobre o melhor interesse da criança, impedindo-lhe de obter o reconhecimento jurídico daquilo que já é fato: o status de filha e integrante legítima do núcleo familiar formado pelos pares homoafetivos. Imperioso reconhecer o progresso para o qual é encaminhada a sociedade e acompanhar suas transformações, de modo a preencher as lacunas que se abrem em decorrência de tais modificações. $O$ julgador há de auxiliar no progresso do Direito, fazendo que as relações de família se adequem à vontade da sociedade, que há de ser a da obtenção da felicidade mais ampla e geral dos envolvidos, pela realização dos sentimentos mais caros e não se constituir de obstáculo a isto, sobremaneira se não há choque algum com o mundo jurídico. Não se pode sonegar prerrogativas aos casais homossexuais por sua sexualidade. [...] (grifo nosso)

Extrai-se do trecho grifado supra que o julgador, ao tomar mencionada decisão, leva em consideração o princípio do melhor interesse da criança, ao garantir que a criança seja registrada pelos dois pais, que são as pessoas que de fato constituem a sua família. Ainda, denota-se que não houve discriminação sexual neste caso, uma vez que o julgador não usou o fato do casal ser homoafetivo como fato desabonador.

Lorem

[...] Não há aparato jurídico para tanto. 5 CENTRO DE APOIO OPERACIONAL DAS PROMOTORIAS DE JUSTIÇA CÍVEIS, FALIMENTARES, DE LIQUIDAÇÕES EXTRAJUDICIAIS, DAS FUNDAÇÕES E DO TERCEIRO SETOR Excerto: (...) Sustenta, ainda, que a competência para análise dos autos é do Juízo da Infância e Juventude, por ter a gestora em substituição, M. B. C., irmã de J. C., doado seu gameta na composição da inseminação artificial. Deste modo, por ser mãe biológica da menor, ao renunciar ao poder familiar, à demanda deve ser conferido, em lugar de declaração de dupla paternidade, o caráter de adoção unilateral, já que para a viabilidade da primeira o gameta necessitaria ter sido concedido por doadora anônima. As hipóteses aventadas, contudo, não merecem prosperar. Inicialmente, é de bom alvitre tecer alguns comentários sobre adoção. [...] Em outras palavras, além de um ato de amor que percorre mão dupla - pois, se de um lado, está a possibilidade de dar filhos àqueles a quem a natureza negou, de outro, encontra-se um propósito assistencial em que há um meio de propiciar melhores condições morais e materiais ao adotado -, adoção é o acolhimento de uma nova família, através de pais generosos, ao infante por vezes amargo e sofrido que, por razões diversas, fora abandonado ou rejeitado por seus genitores, e que se torna possível a partir da perda do poder familiar de seus pais biológicos com relação ao descendente. Nessa senda, exata é a premissa de que a competência para julgamento de ações de adoção é da Vara da Infância e da Juventude. Não é este, contudo, o cenário presente, pois a menina em questão jamais sofreu abandono ou rejeição, e tudo que historiam os autos é um projeto de montagem de uma família com os avanços que a ciência atualmente alcançou na área da reprodução humana. (TJ-SC, Apelação Cível n. 2014.079066-9, da Capital, rel. Des. Domingos Paludo, j. 12-03-2015) - grifei.

A decisão supra revela uma tendência dos tribunais, qual seja, priorizar o princípio do melhor interesse da criança independente do viés biológico, uma vez que a família da criança já estava formada pelos dois pais muito antes do nascimento e que, exclusivamente por isso, foi planejada a geração da criança.

Nessa mesma linha, outra decisão que merece destaque, foi proferida pela $3^{\text {a }}$ Vara de Família do Tribunal de Justiça do Ceará, a qual reconheceu a maternidade socioafetiva dupla de uma criança, cujo doador genético relacionou-se com uma 
das mulheres apenas com o intuito de contribuir com o material genético, sem intenção de ver seu nome registrado ou participar da vida da criança.

Observa-se essa situação também na "inseminação artificial caseira”, que segundo a Anvisa (2018), "a prática envolve basicamente a coleta do sêmen de um doador e sua inseminação imediata em uma mulher com uso de seringa ou outros instrumentos, como cateter.".

Nota-se que os casais, principalmente os homoafetivos constituídos por duas mulheres, têm recorrido a este método pela dificuldade de acesso às demais formas de reprodução assistida regulamentadas e pelo baixo (ou nenhum) custo que envolve a inseminação artificial caseira. Percebe-se que, além de enfrentar os riscos de esse procedimento, o casal ainda enfrenta a dificuldade para registrar a criança, uma vez que esta técnica não é reconhecida pela Resolução do Conselho Federal de Medicina $\mathrm{n}^{\circ}$ 2.121/2015, que elenca os requisitos que a reprodução assistida deve atender, quais sejam:

3 - Nas clínicas de reprodução assistida, os seguintes documentos e observações deverão constar no prontuário do paciente: 3.1. Termo de consentimento livre e esclarecido informado assinado pelos pacientes e pela doadora temporária do útero, contemplando aspectos biopsicossociais e riscos envolvidos no ciclo gravídico-puerperal, bem como aspectos legais da filiação; 3.2. Relatório médico com o perfil psicológico, atestando adequação clínica e emocional de todos os envolvidos; 3.3. Termo de Compromisso entre os pacientes e a doadora temporária do útero (que receberá o embrião em seu útero), estabelecendo claramente a questão da filiação da criança; 3.4. Garantia, por parte dos pacientes contratantes de serviços de RA, de tratamento e acompanhamento médico, inclusive por equipes multidisciplinares, se necessário, à mãe que doará temporariamente o útero, até o puerpério; 3.5. Garantia do registro civil da criança pelos pacientes (pais genéticos), devendo esta documentação ser providenciada durante a gravidez; 3.6. Aprovação do cônjuge ou companheiro, apresentada por escrito, se a doadora temporária do útero for casada ou viver em união estável.

Assim, percebe-se que, além da dificuldade de gerar um filho, os casais passam pela barreira do registro de nascimento que, em muitos casos, impede que conste o nome das duas mães ou dois pais na certidão e nascimento.

Em São Paulo, um casal homoafetivo constituído por duas mulheres utilizou dessa técnica para a concepção da criança. No caso, uma das mães ao tenta registrar a criança com nome de ambas viu-se impedida pelo cartório de fazê-lo, o que fez o casal buscar por meio judicial este direito, o qual foi concedido pelo juiz.

Da mesma forma, em Lajeado/RS, foi julgado pelo Tribunal de Justiça do Rio Grande do Sul um caso similar, em que foi deferido o pedido de registro no nome das duas mães. Observa-se que o pedido foi deferido para que constasse o nome das duas mães na certidão de nascimento sem nenhum óbice. O juiz fundamenta a sentença da seguinte forma:

[...] Assim, no evento sub oculis, considerando a ausência de regulamentação legislativa específica, e não vislumbrando qualquer indício de ilegalidade, tenho que a melhor solução que se anuncia consiste no deferimento do pedido de urgência apresentado, autorizando que p registro de nascimento nascituro seja efetuado em nome de Mãe 1 e Mãe 2. Indubitável que a medida requestada soa por demasiado recomendada para os interesses da criança. Ao exposto, JULGO PROCEDENTE o pedido apresentado por Mãe 1 e Mãe 2 para determinar que o nascituro daquela seja registrado em nome das duas requerentes, devendo ainda ser lançados os dados atinentes às ascendências maternas, constantes dos documentos juntados na HABILITAÇÃO4 que aparelha a petição inicial.

Denota-se dos julgados supra que, diante desse novo cenário, percebe-se que já há nos nossos tribunais o reconhecimento da dupla paternidade ou dupla maternidade socioafetiva e, consequentemente permite a renúncia do doador do material genético, haja vista que a pessoa somente teve a intenção de contribuir geneticamente, sem qualquer interesse na participação na vida da criança e, assim, preponderando atender o princípio do melhor interesse da criança.

\section{Considerações Finais}

Este artigo teve por objetivo verificar se os tribunais estão levando em consideração o princípio do melhor interesse da criança ao decidirem apenas pelo reconhecimento da família socioafetiva, constituída por dois pais ou duas mães, nos casos 
de gestações com multiplicidade de vínculos parentais em face de doação de material genético por terceiro.

No que tange a questão acerca da sociedade contemporânea, as novas configurações de família constituem uma evolução natural da sociedade, sendo necessário que o direito acompanhe tais avanços técnicos que surgem socialmente. Por outro lado, nem sempre isso ocorre, porquanto as interações sociais sucedem-se de maneira mais rápida do que o direito consegue acompanhar. Assim, embora não haja legislação que contemple amplamente todas as formas de constituição familiar, a doutrina e a jurisprudência começaram a reconhecer e a agir no sentido de respaldar esses novos arranjos familiares.

Antes de analisar se o posicionamento adotado pelos Tribunais Brasileiros se adapta às necessidades, bem como a realidade da sociedade atual, foi necessário abordar a evolução do instituto do Direito de Família no Brasil, compreender a paternidade e a maternidade socioafetiva analisando os elementos constitutivos e os efeitos de seu reconhecimento e, finalmente apontar o entendimento dos tribunais acerca do princípio da afetividade nas relações familiares.

Assim, é possível constatar que há casais que recorrem às diversas técnicas para ter filhos, sendo uma delas a gestação por substituição ou a inseminação artificial caseira. Estas técnicas não estão contempladas pela legislação brasileira e em face disso os casais se deparam com dificuldades para registrar a criança com o nome das duas mães ou dois pais além de buscar a exclusão do doador do material genético quando conhecido. De igual forma, constata-se pelas jurisprudências pesquisadas que há a possibilidade de excluir o nome do doador do material genético, uma vez que este ocupa apenas este papel e não faz parte da configuração familiar prévia, ou seja, não tem qualquer vínculo afetivo e de convivência com a criança, além de não querer fazer parte dessa configuração.

Por fim, observa-se que o objetivo da pesquisa foi alcançado, sendo possível verificar que o posicionamento dos Tribunais abordados no presente artigo é no sentido de atender ao princípio do melhor interesse da criança, com fito de facilitar o processo de registro do infante a fim de priorizar e garantir o direito de viver em família, contudo deve-se destacar que as relações familiares são complexas e cada caso tem sido analisado e decidido conforme suas particularidades.

A partir da pesquisa realizada observa-se a pertinência da temática no campo jurídico-familiar, restando claro a necessidade de novos estudos com o propósito de averiguar a evolução dos vinculos multiparentais, bem como seus respectivos reflexos jurídicos.

\section{Referências}

Abrantes Neto, O. N. de, Melo, A. M. M. de, \& Santos, V. E. da S. (2020). A multiparentalidade no Brasil: A concretização dos direitos e garantias da criança e do adolescente. Research, Society and Development, 9(1), e134911802. https://doi.org/10.33448/rsd-v9i1.1802
Ascom/Anvisa.
(2018).
Inseminação
Artificial
Caseira:
riscos
e
cuidados.

http://www.blog.saude.gov.br/index.php?option=com_content\&view=article \&id=53303\&catid=564\&Itemid=50022

Assembleia Geral da ONU. (1948). "Declaração Universal dos Direitos Humanos" (217 [III] A). Paris.

Brasil. (1988). Constituição da República Federativa do Brasil, de 05 de outubro de 1988. In: Diário Oficial da República Federativa do Brasil.

Brasil. (2017). Conselho Nacional de Justiça (CNJ). Provimento 63/2017. https://atos.cnj.jus.br/atos/detalhar/2525.

Brasil. (2019). Conselho Nacional de Justiça (CNJ). Provimento 83/2019. https://atos.cnj.jus.br/atos/detalhar/2975.

Brasil. (1990). Lei $\mathrm{n}^{\mathrm{o}}$ 8.069, de 13 de julho de 1990. Dispõe sobre o Estatuto da Criança e do Adolescente. http://www.planalto.gov.br/ccivil_03/leis/18069.htm.

Brasil. (2016). Supremo Tribunal Federal. Recurso Extraordinário 898.606. http://www.stf.jus.br/arquivo/cms/noticiaNoticiaStf/anexo/RE898060.pdf.

Brasil. (2016). Supremo Tribunal Federal. Paternidade socioafetiva não exime de responsabilidade o pai biológico. http://www.stf.jus.br/portal/cms/verNoticiaDetalhe.asp?idConteudo=325781.

Bôas, R. M. V. (2020). Inseminação artificial caseira: sabia que isso é possível? http://estadodedireito.com.br/inseminacao-artificial-caseira-sabia-que-isso-epossivel/.

Conselho Federal de Medicina. (2015). Resolução CFM 2.121/2015. http://www.portalmedico.org.br/resolucoes/CFM/2015/2121_2015.pdf. 
Research, Society and Development, v. 10, n. 8, e51510815753, 2021

(CC BY 4.0) | ISSN 2525-3409 | DOI: http://dx.doi.org/10.33448/rsd-v10i8.15753

Dias, M. B. (2001) Evolução feminina, como se

http://www.mariaberenice.com.br/manager/arq/(cod2_728)10_evolucao_feminina_como_se_insere_na_familia.pdf .

Dias, M. B. (2016). Manual de Direito das Famílias. 4 ed., Revista dos Tribunais.

Gonçalves, C. R. (2017). Direito civil brasileiro, vol. 6, 14. ed., Saraiva.

Instituto Brasileiro de Direito de Família (IBDFAM). (2014). Criança pode ser registrada com nomes de dois pais em caso de gestação por substituição. http://www.ibdfam.org.br/noticias/5407/Crian\%C3\%A7a+pode+ser+registrada+com+nomes+de+dois+pais+em+caso+de+gesta\%C3\%A7\%C3\%A3o+por+su bstitui $\%$ C3\% A7\% $3 \% \mathrm{~A} 30$.

Instituto Brasileiro de Direito de Família (IBDFAM). (2019). TJCE reconhece maternidade socioafetiva dupla. http://www.ibdfam.org.br/noticias/6958/TJCE+reconhece+maternidade+socioafetiva+dupla.

Lôbo, P. L. N. (2003). Código Civil Comentado, vol. XVI, Coord. Azevedo, Á. V. Atlas.

Madaleno, R. (2018). Direito de família. 8. ed., Rev., Atual. e Ampl, Forense.

Machado, M. T. (2003). A proteção constitucional de Crianças e Adolescentes e os Direitos Humanos, 1 Ed. Manole.

Migalhas. (2019). Criança que nasceu de inseminação artificial caseira será registrada com nome das duas mães. https://www.migalhas.com.br/quentes/312872/crianca-que-nasceu-de-inseminacao-artificial-caseira-sera-registrada-com-nome-das-duas-maes

Minayo, M.C.S. (1983). Quantitativo-Qualitativo: oposição ou complementaridade. Cadernos de Saúde Pública. v.9, n.3, pp.239-262.

Moraes, M. C. B. (2013). A nova família, de novo - Estruturas e função das famílias contemporâneas. Pensar, vol. 18, n. 2, p. 587-628. https://periodicos.unifor.br/rpen/article/view/2705/pdf .

Pereira, C. M. S. (2018). Instituições de Direito Civil. vol. 5, 26. Ed. Forense.

Popper, K. S. (1975). A lógica da pesquisa científica. 2. ed. Cultrix.

Portal Médico. (2015). RESOLUÇÃO CFM nº 2.121/2015. http://www.portalmedico.org.br/resolucoes/CFM/2015/2121_2015.pdf. 